This authors' personal copy may not be publicly or systematically copied or distributed, or posted on the Open Web, except with written permission of the copyright holder(s). It may be distributed to interested individuals on request.

\title{
Influence of atmospheric teleconnection patterns on airborne pollen levels in the NE Iberian Peninsula
}

\author{
Rebeca Izquierdo ${ }^{1}$, Marta Alarcón ${ }^{1, *}{ }^{,}$, Husam T. Majeed ${ }^{1}$, Cristina Periago ${ }^{1}$, \\ Jordina Belmonte ${ }^{2,3}$
}

\footnotetext{
${ }^{1}$ Departament de Física i Enginyeria Nuclear, Universitat Politècnica de Catalunya, C/ Urgell 187, 08036 Barcelona, Spain ${ }^{2}$ Institut de Ciencia i Tecnologia Ambientals (ICTA), Universitat Autònoma de Barcelona (UAB), Edifici Z, 08193 Bellaterra, Spain ${ }^{3}$ Departament de Biologia Animal, Biologia Vegetal i Ecologia, Universitat Autònoma de Barcelona (UAB), Edifici C, 08193 Bellaterra, Spain
}

\begin{abstract}
Using 22 pollen taxa collected at 6 localities in Catalonia (NE Spain) during the period 1994-2011, we show that climate variability associated with Northern Hemisphere teleconnection patterns (North Atlantic Oscillation, Arctic Oscillation and Western Mediterranean Oscillation) affects both seasonal pollen production and the timing of the airborne pollen season. For most of the studied pollen taxa, positive phases of the 3 climatic indices were related to a decrease in the seasonal pollen index and an advance and enlargement of the pollen season. Furthermore, for most taxa, negative phases of the climatic indices were linked to higher pollen production via an increase in rainfall. A clear relationship between climatic indices and the end of the pollen season was not observed. Since pollen parameters correlate more strongly with the Western Mediterranean Oscillation index (WeMOi) than other indices, the WeMOi negative trend observed over the last decades needs to be confirmed to properly identify its effect on ecosystems and public health in the western Mediterranean basin.
\end{abstract}

KEY WORDS: NAO $\cdot \mathrm{AO} \cdot \mathrm{WeMO} \cdot$ Seasonal Pollen Index $\cdot$ Pollination $\cdot$ Western Mediterranean

\section{INTRODUCTION}

The influence of climate and climatic changes on ecosystems has often been mentioned in the literature in recent years (Walther 2010). It is apparent that large-scale climate variability affects ecosystems not through a single weather variable, but rather through a combination of weather features (Stenseth \& Mysterud 2005). Climate change may result in an increase in the frequency of extreme events which are more relevant in the phenology of the ecosystems than fluctuations in the mean climate (Stenseth et al. $2002,2003)$. Climate indices reducing complex space and time variability and gathering different climatic variables into simple measures have been shown to be of great use in the field of ecology. One of the more interesting climate indices in terms of correla- tion with ecological processes in the Northern Hemisphere is the North Atlantic Oscillation (NAO) index (Barnston \& Livezey 1987). The NAO is one of the major driving forces of the climate system of the Northern Hemisphere (Hurrell 1995) that quantifies the interannual variability in the atmospheric circulation of the northern Atlantic region. The NAO index (NAOi) is based on the sea level pressure difference between the sub-polar low-pressure center over Iceland and the subtropical high-pressure center over the Azores (Tildes Gomes 2000, Stenseth et al. 2002). Many studies have discussed the databases of the different meteorological stations - Punta Delgada, Lisbon, Gibraltar, Reykjavik, Akureyri, Stykkisholmur, among others - that could be used to measure this difference of pressure (Hurrell 1995, Jones et al. 1997, Osborn 2006). For the purposes of this study, 
the NAOi is defined as the difference between the normalized pressure anomaly at Gibraltar (Iberian Peninsula) and Reykjavik (southwestern Iceland).

According to Hurrell (1995), the NAO is the main large-scale pattern that influences the variability of the Euro-Mediterranean climate. The NAO regulates the cyclone trajectories and cyclogenesis in the Mediterranean area that influence its climatic variability (Bolle 2003). This phenomenon is particularly important in the western Mediterranean region, which is strongly affected by the NAO atmospheric dipole (Von Storch et al. 1993). Thus, a positive NAO phase results in a positive level pressure anomaly over the Mediterranean Basin, which, in turn, corresponds to a northward deflection trajectory, followed by Atlantic cyclones and to weaker cyclogenesis in the basin (Hurrell et al. 2003). In other words, a positive NAO phase corresponds to a lower cyclone frequency in the area, less cloud cover and, therefore, greater insolation. So, taking into account that the surface temperature in the Mediterranean area relies heavily on the insolation (Muñoz-Díaz \& Rodrigo 2003) and that temperature has been identified as the most important factor affecting the starting date of pollen seasons in temperate ecosystems (Emberlin et al. 1993, Van Vliet et al. 2002, Galán et al. 2005), the hypothesis that an advance in the pollen seasons of different taxa is correlated with the NAOi can be inferred. In contrast, the NAO negative mode produces high-pressure blocking in the NE Atlantic, with more meridional circulation and wetter conditions in the western Mediterranean.

Some effects of climate variability on plant phenology include advances on some parameters, such as the deployment of new leaves or flowering (Menzel et al. 2006), shifts in the timing of pollen seasons (Jäger et al. 1996, Emberlin et al. 2007), or an increase in the pollen production of different plants (Teranishi et al. 2000, Ziello et al. 2012). According to Clot (2003), atmospheric pollen can be considered a very sensitive indicator of climate variability. For this reason many recent studies have addressed the climate-variability-aerobiology relationship perspective. D'Odorico et al. (2002) were able to find relationships between some phases of the NAO and different parameters of the pollen season. Later, Avolio et al. (2008) found that the climatic interannual variability due to the NAO was unequivocally tied to the olive pollen seasons in Central Italy. More recently, a study by Smith et al. (2009) showed the importance of considering large-scale patterns of climate variability like the NAO for the prediction of the start and magnitude of the grass pollen seasons across Europe.
On the other hand, the western Mediterranean is under the WeMO (Western Mediterranean Oscillation) domain. This recently defined secondary oscillation form in the western Mediterranean basin (Martín-Vide \& López-Bustins 2006) accounts for the eastern Iberian Peninsula regions that are only weakly related, or even completely unrelated to the NAO pattern. The WeMO is defined using the dipole San Fernando (Cadiz, Spain)-Padua (Italy). The positive mode corresponds to high pressure over the SW Iberian Peninsula and low pressure in the Liguria Gulf. In the positive phase, rainfall is more abundant along the Cantabric peninsular coast and less abundant along the Mediterranean coast, primarily representing fluxes over Catalonia from the north (France and northern Iberian Peninsula). Its negative mode is produced when an anticyclone is situated in central Europe and the north of Italy and low pressure is found on the SW Iberian Peninsula. In this negative phase, fluxes over Catalonia are predominantly from the Mediterranean Sea and northern Africa and wetter conditions occur over the eastern coast of the Iberian Peninsula and the Ebro basin.

There is another natural mode of variability that greatly affects Europe and the Mediterranean area, the Arctic Oscillation (AO), which represents the state of atmospheric circulation over the Arctic (López-Bustins et al. 2008). The AO is defined as the first principal component time-series of the mean sea-level pressure field over the Northern Hemisphere, north of $20^{\circ}$ (Stenseth et al. 2003). Although there is a high correlation between the $\mathrm{AO}$ and NAO, the basic physical mechanisms are different (Zhou et al. 2001). While the NAO refers to a local mechanism associated with a physical dipole affecting the North Atlantic, the AO has a zonal structure reflecting the variations of the circumpolar flow (Ambaum et al. 2001). In its positive mode, lower-than-normal pressures over the polar region are registered, driving Atlantic storms northward and, thereby, wetter weather over northern Europe and drier conditions in Mediterranean regions.

In short, positive phases of the NAO, WeMO and $\mathrm{AO}$ indices reflect sunnier and drier conditions in Catalonia and their negative phases coincide with wetter and rainier conditions.

The most recent studies on the subject have focused on the spatial variability of the pollination seasons in relation to the NAO index (Stach et al. 2008a,b, Smith et al. 2009, Dalla Marta et al. 2011), but, for instance, there have been no studies to assess the influence of the NAO over the different taxa representative of the surrounding vegetation. No studies 
have been done relating airborne pollen data with WeMO and AO indices.

In this study, we aim to investigate the correlation between the NAO, WeMO and AO indices and the main standardized airborne pollen parameters (Seasonal Pollen Index, Start, End and Length of the airborne pollen season) of 22 taxa collected at 6 localities in Catalonia (NE Spain) during the $18 \mathrm{yr}$ period from 1994 to 2011, in order to determine the effect of climate variability on the pollen dynamics.

\section{MATERIALS AND METHODS}

\subsection{Pollen records}

Airborne pollen data were recorded by the Aerobiological Network of Catalonia at 6 stations located in Barcelona and Bellaterra, for the $18 \mathrm{yr}$ period from 1994 to 2011, and in Girona, Lleida, Manresa and Tarragona, for the 16 yr period from 1996 to 2011 (Fig. 1). Samples were obtained daily from Hirst samplers (Hirst 1952), the standardized method in European aerobiological networks, and analyzed following the standardized Spanish method (see Galán Soldevilla et al. 2007). The Seasonal Pollen Index (SPI, sum of the mean daily pollen concentrations in a year for the pollen season) has been used as the measure of pollen and has been obtained for 22 pollen taxa considered of high interest due to abundance, landscape importance and/or allergenic significance: Alnus, Ambrosia, Artemisia, Betula, Castanea, Chenopodiaceae/Amaranthaceae, Corylus, Cupressaceae, Fagus, Fraxinus, Olea, Pinus, Pistacia, Plantago, Platanus, Poaceae, Polygonaceae, total Quercus, Quercus deciduous type, Quercus evergreen type, Ulmus and Urticaceae (Table 1).
The pollen parameters studied were: the SPI, the dates of the Start and End of the pollen season and the Length of the season (number of days between Start and End). We define the pollen season as the period between the date (Start) in which the sum of the daily mean pollen concentrations reaches $2.5 \%$ of the annual sum, and the date (End) in which the sum reaches 97.5\% (after Andersen 1991).

\subsection{Climatic indices}

The NAO (available at https://climatedataguide. ucar.edu/climate-data/hurrell-north-atlantic-oscillationnao-index-stationbased; Hurrell et al. 2014), the WeMO (available at www.ub.edu/gc/English/wemo. htm; Group of Climatology, University of Barcelona) and the AO (available at www.cpc.ncep.noaa.gov/ products/precip/CWlink/daily_ao_index/ao_index. shtml; NOAA/National Center for Environmental Prediction, Climate Prediction Center) indices were correlated with SPI and Start, End and Length of the pollen season. Standardized data (obtained by subtracting the mean and dividing by the standard deviation) were used in the SPI and the climatic indices. The Spearman rank correlation coefficient (Spearman's rho) was applied to measure the relationship between the pollen data and the climatic indices.

Considering that the climatic indices show their most relevant dynamics during the cold months, both the annual and the winter (December to March) indices were used. However, the correlations between SPI and the summer NAO (SNAO; July to August) were also computed. Though less robust and extensive than their counterpart, the SNAO is nonetheless a prominent feature of summer atmospheric variability in the North Atlantic/European sector,

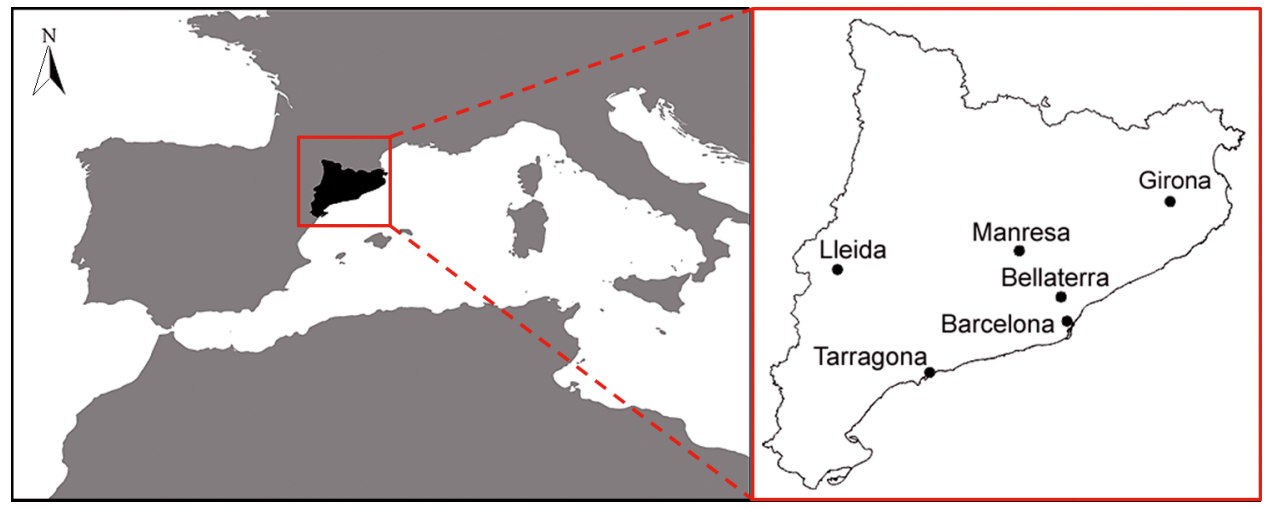

Fig. 1. Study area and sampling stations of the Aerobiological Network of Catalonia: Barcelona, Bellaterra, Girona, Lleida, Manresa and Tarragona 
Table 1. Annual means of total pollen for the taxa under study (pollen grains $\mathrm{yr}^{-1}$ ), and the percentage of each individual taxon at the 6 sampling stations for the period 1994-2011

\begin{tabular}{|c|c|c|c|c|c|c|c|}
\hline Pollen taxon & Barcelona & Bellaterra & Girona & Lleida & Manresa & Tarragona & Catalonia \\
\hline Total pollen (grains $\mathrm{yr}^{-1}$ ) & 42747 & 39784 & 55498 & 31938 & 43555 & 32874 & 41066 \\
\hline Alnus $(\%)$ & 0.37 & 0.38 & 1.27 & 1.62 & 0.35 & 0.26 & 0.72 \\
\hline Ambrosia (\%) & 0.02 & 0.03 & 0.01 & 0.02 & 0.01 & 0.01 & 0.02 \\
\hline Artemisia (\%) & 0.34 & 0.42 & 0.15 & 1.18 & 0.42 & 0.69 & 0.48 \\
\hline Betula (\%) & 0.46 & 0.46 & 0.54 & 0.23 & 0.32 & 0.40 & 0.42 \\
\hline Castanea (\%) & 0.59 & 0.41 & 0.99 & 0.22 & 0.23 & 0.54 & 0.53 \\
\hline $\begin{array}{l}\text { Chenopodiaceae/ } \\
\text { Amaranthaceae (\%) }\end{array}$ & 1.24 & 1.21 & 0.77 & 12.9 & 2.20 & 1.79 & 2.89 \\
\hline Corylus $(\%)$ & 0.53 & 0.56 & 0.96 & 0.32 & 0.47 & 2.99 & 0.92 \\
\hline Cupressaceae (\%) & 16.1 & 16.6 & 12.2 & 25.5 & 18.3 & 27.4 & 18.4 \\
\hline Fagus (\%) & 0.04 & 0.05 & 0.13 & 0.06 & 0.04 & 0.04 & 0.07 \\
\hline Fraxinus (\%) & 0.66 & 0.68 & 3.21 & 0.83 & 0.93 & 1.07 & 1.36 \\
\hline Olea $(\%)$ & 2.89 & 2.73 & 1.57 & 6.74 & 5.45 & 9.37 & 4.38 \\
\hline Pinus (\%) & 11.2 & 20.3 & 12.4 & 8.18 & 15.6 & 12.6 & 13.5 \\
\hline Pistacia (\%) & 0.17 & 0.30 & 0.12 & 0.24 & 0.42 & 0.35 & 0.26 \\
\hline Plantago (\%) & 0.92 & 2.46 & 1.27 & 3.08 & 8.66 & 1.57 & 2.98 \\
\hline Platanus (\%) & 37.2 & 10.3 & 9.35 & 5.35 & 12.3 & 4.07 & 13.6 \\
\hline Poaceae $(\%)$ & 2.62 & 3.76 & 3.78 & 7.21 & 5.49 & 3.75 & 4.32 \\
\hline Polygonaceae (\%) & 0.18 & 0.19 & 0.24 & 0.43 & 0.17 & 0.24 & 0.23 \\
\hline Quercus & 11.5 & 18.1 & 28.1 & 11.5 & 11.6 & 12.0 & 16.4 \\
\hline Quercus deciduous type (\%) & 2.36 & 5.65 & 9.96 & 2.35 & 2.82 & 1.93 & 4.62 \\
\hline Quercus evergreen type (\%) & 9.13 & 12.5 & 18.2 & 9.13 & 8.81 & 10.1 & 11.8 \\
\hline Ulmus (\%) & 0.30 & 0.67 & 0.19 & 0.21 & 0.71 & 0.86 & 0.47 \\
\hline Urticaceae (\%) & 6.76 & 5.46 & 5.75 & 3.29 & 7.53 & 10.3 & 6.49 \\
\hline Sum $(\%)$ & 94.1 & 85.1 & 83.0 & 89.2 & 91.3 & 90.4 & 88.5 \\
\hline
\end{tabular}

which significantly affects precipitation in the Mediterranean area (Bladé et al. 2012).

\section{RESULTS}

Table 1 shows the percentage of each individual pollen taxon collected at the 6 sampling stations, and the annual mean of total pollen (expressed in pollen grains per year) for the 1994-2011 period. The 22 pollen taxa selected accounted for 83 to $94 \%$ of the total pollen.

\subsection{Climatic indices}

In the $18 \mathrm{yr}$ period analyzed here (Table 2), the NAO and AO showed a high positive Spearman bivariate correlation in both their annual $(0.794, \mathrm{p}<$ $0.001)$ and winter $(0.796, \mathrm{p}<0.001)$ dynamics, and a weaker but still significant correlation $(0.507, \mathrm{p}<0.05)$ between the NAO annual and the AO winter indices. Regarding the WeMOi, the winter index showed a positive correlation $(0.645, \mathrm{p}<0.001)$ with the NAO winter index but a weak and non-significant positive correlation between their annual values. No correlation was found between the WeMOi and AOi.

Fig. 2 shows the decadal trends of climatic indices. Annual and winter trends of the NAO, AO and WeMO indices were negative during the 1994-2011 period, but only the declining trend in the annual WeMOi was significant $\left(R^{2}=0.504, p=0.001\right)$.

\subsection{SPI relationship with annual and winter climatic indices}

In general, seasonal airborne pollen levels (SPI) measured at the 6 sampling stations correlated better with the WeMOi (a total of 34 significant Spearman correlations) than with the NAOi (17) and AOi (7) (Table 3). All taxa presented significant correlations with at least 1 of the indices at a minimum of 1 of the stations, except Alnus, Ambrosia, Betula, Fagus and Polygonaceae which did not present any (Table 4). Bellaterra was the station with the most correlations (19), followed by Barcelona (13), Lleida (10) and Manresa (8), while Tarragona and Girona were the stations with the fewest correlations (4) (Table 4). 
Results of Spearman correlations between SPI and the 3 climatic indices (Table 4), which are detailed thereafter, correspond to significant correlations at at least 1 of the monitoring stations. Artemisia, Cupressaceae, Fraxinus, Olea, Pinus, Plantago, total Quercus, Quercus deciduous type, Quercus evergreen type, Ulmus and total pollen were inversely correlated with the climatic indices, while Castanea, Chenopodiaceae/Amaranthaceae, Corylus and Pistacia were positively correlated. Platanus, Poaceae and Urticaceae showed both negative and positive correlations. Corylus, with 8 positive correlations, was the pollen taxon with the highest number of correlations, as well as the most sensitive taxon to the annual NAOi variability, although $71 \%$ of the significant correlations between SPI and climatic indices were negative.

Spearman correlations were also carried out for the average SPI data of the 6 stations, as representative of the mean behavior in Catalonia (for further details see Table S1 in the Supplement at www.int-res.com/ articles/suppl/c066p171_supp.pdf). Results showed no significant correlations between SPI and the climatic indices in Catalonia for Alnus, Ambrosia, Betula, or Fagus, nor for Castanea, Fraxinus, Pistacia, Platanus, or Urticaceae. Conversely, Polygonaceae were negatively correlated with the winter WeMOi. The rest of the taxa showed negative correlations, excepting Corylus, which was positively correlated with the annual NAOi and AOi. WeMOi was the index with the highest number of correlations (13), and these were negative, while AOi only showed 1 correlation with the annual index, and this was positive.

Finally, negative correlations between the SNAOi and SPI (Table 5) were observed for: Ambrosia, Chenopodiaceae/Amaranthaceae, Fraxinus, Olea, Pinus, Platanus, total Quercus, Quercus evergreen type, Ulmus and Urticaceae. The SNAOi was only positively correlated with the SPI of Ambrosia in Girona, and no correlations were found among the rest of the pollen taxa.

\subsection{Influence of climatic indices in the Start, End and Length of the pollen season}

The influence of the $\mathrm{NAO}_{\mathrm{i}}, \mathrm{WeMO}_{\mathrm{i}}$ and $\mathrm{AO}_{\mathrm{i}}$ in the dates at which pollination occurs was evaluated (Tables S2-S4 in the Supplement at www.int-res.com /articles/suppl/c066p171_supp.pdf). Different behaviors between stations were found, showing the most significant correlations in Bellaterra (a total of 42 sig- 

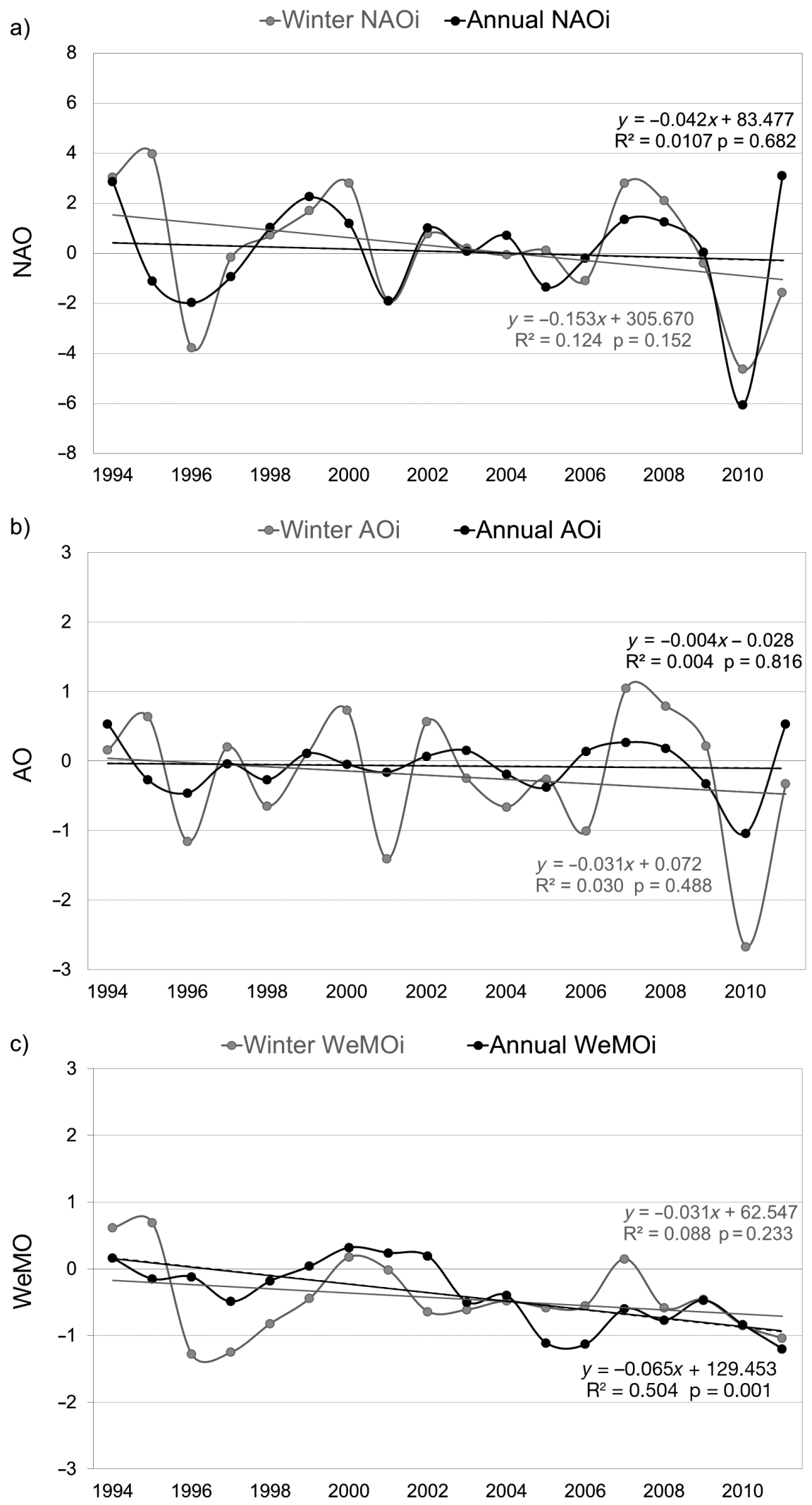

Fig. 2. Winter and annual trends of: (a) North Atlantic Oscillation (NAO), (b) Arctic Oscillation (AO) and (c) Western Mediterranean Oscillation (WeMO) indices for the 1994-2011 period 
Table 3. Number of significant Spearman correlations $(\mathrm{p}<$ 0.05) between pollen parameters (Seasonal Pollen Index [SPI], Start, End and Length) versus winter (w; from December to March) and annual (a) climatic indices (see Table 2 for index abbreviations) at the 6 sampling stations for the period 1994-2011. N: negative correlation; P: positive correlation

\begin{tabular}{|c|c|c|c|c|c|c|}
\hline & w/a & $\mathrm{N}$ & $\mathrm{P}$ & & Totals & \\
\hline \multicolumn{7}{|l|}{ NAO } \\
\hline \multirow[t]{2}{*}{ SPI } & $\mathrm{w}$ & 9 & 2 & 11 & 17 & 60 \\
\hline & a & 1 & 5 & 6 & & \\
\hline \multirow[t]{2}{*}{ Start } & w & 7 & 3 & 10 & 21 & \\
\hline & a & 11 & 0 & 11 & & \\
\hline \multirow[t]{2}{*}{ End } & w & 1 & 2 & 3 & 10 & \\
\hline & a & 7 & 0 & 7 & & \\
\hline \multirow[t]{2}{*}{ Length } & w & 2 & 4 & 6 & 12 & \\
\hline & $\mathrm{a}$ & 3 & 3 & 6 & & \\
\hline \multicolumn{7}{|l|}{ WeMO } \\
\hline \multirow[t]{2}{*}{ SPI } & $\mathrm{w}$ & 14 & 1 & 15 & 34 & 110 \\
\hline & $\mathrm{a}$ & 14 & 5 & 19 & & \\
\hline \multirow[t]{2}{*}{ Start } & w & 3 & 0 & 3 & 23 & \\
\hline & a & 16 & 4 & 20 & & \\
\hline \multirow[t]{2}{*}{ End } & $\mathrm{w}$ & 2 & 5 & 7 & 23 & \\
\hline & a & 4 & 12 & 16 & & \\
\hline \multirow[t]{2}{*}{ Length } & $\mathrm{w}$ & 3 & 7 & 10 & 30 & \\
\hline & a & 2 & 18 & 20 & & \\
\hline \multicolumn{7}{|l|}{ AO } \\
\hline \multirow[t]{2}{*}{ SPI } & $\mathrm{w}$ & 1 & 2 & 3 & 7 & 43 \\
\hline & a & 2 & 2 & 4 & & \\
\hline \multirow[t]{2}{*}{ Start } & w & 9 & 1 & 10 & 18 & \\
\hline & a & 8 & 0 & 8 & & \\
\hline \multirow[t]{2}{*}{ End } & $\mathrm{w}$ & 5 & 0 & 5 & 11 & \\
\hline & a & 5 & 1 & 6 & & \\
\hline \multirow[t]{2}{*}{ Length } & $\mathrm{w}$ & 1 & 1 & 2 & 7 & \\
\hline & $\mathrm{a}$ & 3 & 2 & 5 & & \\
\hline
\end{tabular}

nificant Spearman correlations), followed by Lleida (32) and Barcelona (24); Girona was the site which showed the slightest influence (16). Regarding the indices, the greatest number of significant correlations was obtained for WeMOi (76), followed by $\mathrm{NAO}_{\mathrm{i}}(43)$ and $\mathrm{AO}_{\mathrm{i}}(36)$ (Table 3). The pollen season parameter with the highest number of correlations was Start (62), followed by Length (49) and End (44) (Table 3).

Spearman correlations between the Start of the pollen season and the climatic indices were mainly negative, which accounted for $87 \%$ of the total correlations (Table 6; Table S2 in the Supplement). Negative correlations were obtained for Alnus, Ambrosia, Artemisia, Cupressaceae, Olea, Pinus, Pistacia, Plantago, Platanus, total Quercus, Quercus deciduous type, Quercus evergreen type, Ulmus and Urticaceae. Platanus was the taxon with the most signifi-

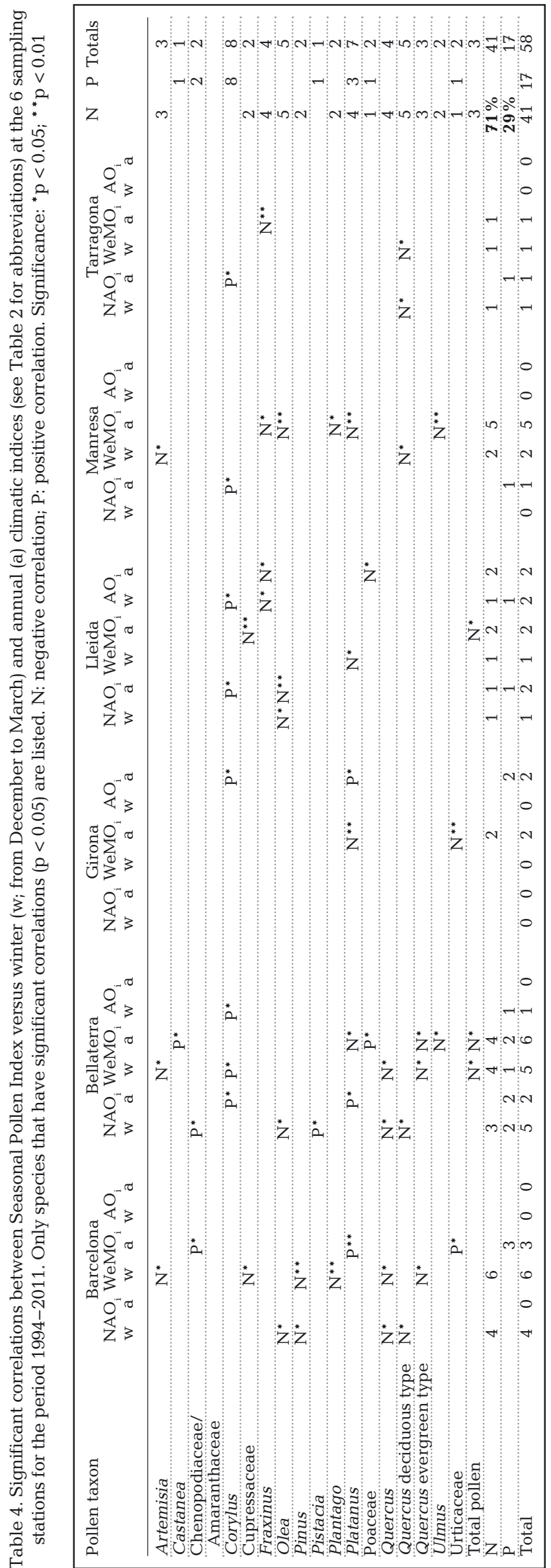


cant correlations (11), followed by Cupressaceae (7), Pistacia and Urticaceae (6). However, Platanus was more sensitive to winter AOi variability, while Cupressaceae and Pistacia were more sensitive to winter NAOi and annual WeMOi, respectively. Positive significant correlations were obtained between Betula, Castanea and Fagus versus winter NAOi, and Castanea and Fagus versus annual WeMOi. Corylus and Polygonaceae showed both negative and positive correlations. Meanwhile, there were no significant correlations with Chenopodiaceae/Amaranthaceae, Fraxinus, or Poaceae.

Fewer significant correlations were obtained with the End of the pollen season (Table 6; Table S3 in the Supplement). The number of positive and negative correlations was balanced; however, negative correlations accounted for $55 \%$ of total correlations. Spearman correlations were negative for Alnus, Artemisia, Betula, Corylus, Pistacia, Platanus, Ulmus and Urticaceae, and positive for Ambrosia, Castanea, Olea, Pinus, Polygonaceae, total Quercus, Quercus deciduous type and Quercus evergreen type. Some taxa showed positive and negative significant correlations depending on the station (Chenopodiaceae/ Amaranthaceae, Fagus, Plantago and Poaceae). Olea was the taxon with the most significant correlations (4), half of them being with the winter WeMOi. No significant correlations were found for Cupressaceae or Fraxinus.

Spearman correlations between Length of the pollen season and the climatic indices (Table 6, Table S4 in the Supplement) were mostly positive, which represented $71 \%$ of the total correlations. Correlations were positive for Artemisia, Cupressaceae, Olea,
Pinus, Pistacia, Poaceae, Polygonaceae, total Quercus, Quercus deciduous type and Quercus evergreen type and Urticaceae. Negative significant correlations were obtained for Alnus, Betula, Corylus, Fraxinus, Plantago and Ulmus. In the case of Fagus and Platanus, positive and negative correlations were obtained, depending on the station. The taxon that exhibited the greatest influence on the Length of the pollen season was Olea (7). Ambrosia, Castanea and Chenopodiaceae/Amaranthaceae did not show significant correlations.

Spearman correlations were also carried out for pollen season parameters with the average values in Catalonia (Table S1 in the Supplement). In this case, the Start date has been established as the earliest Start date registered at the sampling stations, and End, as the latest End date. The Length was the number of days between the Start and the End. The pollen season parameter with the highest number of correlations in Catalonia was Start (14), followed by Length (7) and End (5). Start showed negative correlations for Artemisia, Betula, Cupressaceae, Pinus, Pistacia, Plantago, Platanus, Poaceae, Polygonaceae and Quercus deciduous type, and positive for Castanea and Fraxinus. The rest did not show significant correlations. On the other hand, only 3 significant correlations between the End date and the climatic indices were found. These were negative correlations between Chenopodiaceae/Amaranthaceae, Fagus and Ulmus versus NAO and AO indices. No correlations with the rest of pollen taxa were observed, nor were they observed with WeMOi. Finally, Length for Artemisia, Cupressaceae, Pinus and Quercus deciduous type was positively correlated with the NAOi and

Table 5. Significant Spearman correlations between the summer NAOi (SNAOi) and Seasonal Pollen Index (SPI) at the 6 sampling stations and the mean for Catalonia for the period 1994-2011. Only species that have significant correlations $(\mathrm{p}<0.05)$ are listed. Significance: ${ }^{*} \mathrm{p}<0.05,{ }^{* *} \mathrm{p}<0.01$

\begin{tabular}{|c|c|c|c|c|c|c|c|}
\hline Pollen taxon & Barcelona & Bellaterra & Girona & Lleida & Manresa & Tarragona & Catalonia \\
\hline Ambrosia & $-0.47^{*}$ & & $0.70^{* *}$ & & & & \\
\hline $\begin{array}{l}\text { Chenoppdoaceae/ } \\
\text { Amaranthaceae }\end{array}$ & & & & $-0.67^{* *}$ & & & $-0.51^{*}$ \\
\hline Fraxinus & & & & & & $-0.59^{*}$ & \\
\hline Olea & & & & & & & $-0.50^{*}$ \\
\hline Pinus & & & & & & $-0.55^{*}$ & $-0.47^{*}$ \\
\hline Platanus & & $-0.65^{* *}$ & $-0.53^{*}$ & & $-0.64^{* *}$ & & \\
\hline Quercus & & $-0.60^{* *}$ & & & & & \\
\hline $\begin{array}{l}\text { Quercus ever- } \\
\text { green type }\end{array}$ & & $-0.59^{* *}$ & & & & $-0.55^{*}$ & $-0.49^{*}$ \\
\hline Ulmus & & $-0.48^{*}$ & & & $-0.59^{*}$ & & \\
\hline Urticaceae & $-0.47^{*}$ & & & & & & \\
\hline Total pollen & & $-0.60^{* *}$ & & & & & \\
\hline
\end{tabular}


WeMOi, and for Fagus and Ulmus it was negatively correlated with the NAO and AO annual indices. No significant correlations were found for the rest of the taxa and the annual AOi.

Summarizing, the influence of atmospheric teleconnection patterns on pollen dynamics in Catalonia showed the following. (1) A predominance of negative correlations between SPI and Start date with the climatic indices for most pollen taxa, with the exception of positive correlations between the SPI of Corylus versus annual NAO and AO indices, and the Start date of Castanea and Fraxinus versus the annual WeMOi and winter AOi, respectively. These results suggested an increase of pollen levels and a delay of pollen season for most pollen taxa during the negative phases of climatic indices in Catalonia. (2) An enlargement of the pollen season due to a delay in the end of the pollen season of Fagus and Ulmus can also be expected during the negative phases of the $\mathrm{NAO}$ and AO. (3) A delay in the end of the pollen season of Chenopodiaceae/Amaranthaceae during the negative phases of the NAO and AO has been observed, but, in this case, the pollen season Length

Table 6. Number of significant Spearman correlations $(\mathrm{p}<0.05)$ between Start, End and Length versus the winter (from December to March) and annual climatic indices at the 6 sampling stations for the period 1994-2011. N: negative correlation; P: positive correlation

\begin{tabular}{|c|c|c|c|c|c|c|c|c|c|}
\hline \multirow[t]{2}{*}{ Pollen taxon } & \multicolumn{3}{|c|}{ Start } & \multicolumn{3}{|c|}{ End } & \multicolumn{3}{|c|}{ Length } \\
\hline & $\mathrm{N}$ & $\mathrm{P}$ & Total & $\mathrm{N}$ & $\mathrm{P}$ & Total & $\mathrm{N}$ & $\mathrm{P}$ & Total \\
\hline Alnus & 1 & & 1 & 3 & & 3 & 2 & & 2 \\
\hline Ambrosia & 1 & & 1 & & 1 & 1 & & & 0 \\
\hline Artemisia & 5 & & 5 & 1 & & 1 & & 2 & 2 \\
\hline Betula & & 1 & 1 & 1 & & 1 & 2 & & 2 \\
\hline Castanea & & 3 & 3 & & 1 & 1 & & & 0 \\
\hline $\begin{array}{c}\text { Chenopodiaceae/ } \\
\text { Amaranthaceae }\end{array}$ & & & 0 & 3 & 2 & 5 & & & 0 \\
\hline Corylus & 2 & 1 & 3 & 1 & & 1 & 1 & & 1 \\
\hline Cupressaceae & 7 & & 7 & & & 0 & & 1 & 1 \\
\hline Fagus & & 2 & 2 & 2 & 1 & 3 & 4 & 1 & 5 \\
\hline Fraxinus & & & 0 & & & 0 & 1 & & 1 \\
\hline Olea & 2 & & 2 & & 4 & 4 & & 7 & 7 \\
\hline Pinus & 5 & & 5 & & 1 & 1 & & 5 & 5 \\
\hline Pistacia & 6 & & 6 & 2 & & 2 & & 1 & 1 \\
\hline Plantago & 1 & & 1 & 2 & 1 & 3 & 2 & & 2 \\
\hline Platanus & 11 & & 11 & 2 & & 2 & 1 & 5 & 6 \\
\hline Poaceae & & & 0 & 2 & 1 & 3 & & 1 & 1 \\
\hline Polygonaceae & 2 & 1 & 3 & & 2 & 2 & & 2 & 2 \\
\hline Quercus & 1 & & 1 & & 3 & 3 & & 2 & 2 \\
\hline Quercus deciduous type & 1 & & 1 & & 1 & 1 & & 2 & 2 \\
\hline Quercus evergreen type & 1 & & 1 & & 2 & 2 & & 4 & 4 \\
\hline Ulmus & 2 & & 2 & 3 & & 3 & 1 & & 1 \\
\hline Urticaceae & 6 & & 6 & 2 & & 2 & & 2 & 2 \\
\hline Total & 54 & 8 & 62 & 24 & 20 & 44 & 14 & 35 & 49 \\
\hline Percent (\%) & 87 & 13 & 100 & 55 & 45 & 100 & 29 & 71 & 100 \\
\hline
\end{tabular}

did not show variations. Conversely, results pointed out (4) an enlargement of the pollen season of Artemisia, Cupressaceae, Pinus and Quercus deciduous type during the positive phases of the NAO and WeMO. Finally, (5) the lack of correlation between the pollen season parameters of Alnus, Ambrosia and Urticaceae versus climatic indices suggested that their pollen dynamics in Catalonia were not affected by these teleconnection patterns.

\section{DISCUSSION}

The individual rhythms of plant pollination and phenological phenomena are modified by the effects of atmospheric conditions (Bringfelt et al. 1982, Emberlin et al. 1993). Changes in phenology (seasonal activity driven by environmental factors) from year to year may be a sensitive and easily observable indicator of changes in the biosphere (Menzel \& Fabian 1999, Jochner \& Menzel 2015). Climate variability associated with teleconnection patterns may affect ecological processes such as the breeding phenology of plants. Over the Iberian Peninsula there is strong evidence that positive (negative) values of the winter NAO induce low (high) vegetation activity in the following spring and summer. This feature has mainly been associated with the impact of the NAO on winter precipitation, together with the strong dependence of the spring and summer Normalised Difference Vegetation Index (NDVI) on water availability during the previous winter (Gouveia et al. 2008). Most of the studies of Northern Hemisphere teleconnection patterns focus on the winter months, when the atmosphere is most active dynamically, and perturbations grow to their largest amplitudes (Hurrell \& Deser 2010). In the Mediterranean region, during winter, a strong correlation exists between the regional precipitation patterns and upper-air, largescale circulation anomalies (Quadrelli et al. 2001, Goodess \& Jones 2002). However, during high SNAO summers, when strong anticyclonic conditions and suppressed precipitation prevail over the $\mathrm{UK}_{\text {, the }}$ 
Mediterranean regions are anomalously wet (Bladé et al. 2012).

In this context, the primary aim of this study was to investigate the possible effects of the NAO, WeMO and $\mathrm{AO}$ on pollen production and the timing of the pollen season in wind-pollinated plants in Catalonia (NW Mediterranean area). First, correlations between the 3 climatic indices for the 1994-2011 period were performed. As expected (Thompson \& Wallace 2000, Wallace 2000), high positive correlations between the NAOi and AOi for both annual and winter data were observed. The positive correlation obtained between the winter NAOi and WeMOi is consistent with the $50 \mathrm{yr}$ period 1950-2000 analyzed by Martín-Vide \& López-Bustins (2006), in which the winter WeMOi and NAOi correlated positively, although non-significantly (Pearson: + 0.122, p-value: 0.399). In contrast, a non-significant correlation was found between the WeMOi and $\mathrm{AOi}$, whereas Martín-Vide \& López-Bustins (2006) found a negative correlation for the $50 \mathrm{yr}$ period (Pearson: -0.386 , p-value: 0.005).

Seasonal airborne pollen levels correlated better with the WeMOi than with the NAOi and AOi. Negative correlations between the SPI and climatic indices accounted for $71 \%$ of the total correlations, which indicated the positive effect of precipitation on the annual pollen production for most of the taxa during the negative phase of the 3 indices. In accordance with this study, one can expect a link between increases in winter rainfall in Catalonia during the negative phase of winter climatic indices and increases in pollen production in the following plants: Artemisia, Cupressaceae, Fraxinus, Olea, Pinus, Plantago, total Quercus, Quercus evergreen type and Ulmus, as well as in total pollen. Annual indices were also negatively correlated with these pollen taxa, except Artemisia and Pinus. The Quercus pollen behavior on the NE Iberian Peninsula paralleled patterns observed in Denmark, whereby February precipitation showed a positive influence on Quercus and Corylus pollen accumulation, but the effect was negative for Betula and Tilia (Nielsen et al. 2010). However, biological responses to climate changes could vary depending on the location of the plant; therefore, different responses could be observed for the same species in different areas. This could explain the differences between Corylus and Betula pollen dynamics in Catalonia and Denmark. On the other hand, it is necessary to take into account that the precipitation regime of the previous year may also influence the success of a flower's development and pollen production in the following year of some trees, e.g. Betula (Stach et al. 2008b, Nielsen et al. 2010). This could explain the lack of correlation between the SPI of Alnus, Betula and Fagus and the climatic indices of the same year. In addition, pollen transported from distant regions could mask the correlations between the SPI and climatic indices, since episodes of long-range pollen transport of Ambrosia (Belmonte et al. 2000, Fernández-Llamazares et al. 2012), Corylus (Belmonte et al. 2008a) and Fagus (Belmonte et al. 2008a,b) have been documented in Catalonia.

Precipitation during the flowering season can have a direct negative effect on pollen release and dispersal; daily pollen concentrations in the atmosphere show a clear negative relationship with precipitation (Sommer \& Rasmussen 2008). Precipitation washes pollen out of the atmosphere, so that both intensity and annual distribution of precipitation can be related to the duration and intensity of the pollen season (Jato et al. 2002). Corylus pollinates in winter, consequently positive correlations between the SPI of Corylus and the 3 climatic indices have been interpreted as a washing-out effect. Negative correlations between the SNAOi and SPI of Ambrosia, Chenopodiaceae/Amaranthaceae, Fraxinus, Olea, Pinus, Platanus, total Quercus, Quercus evergreen type, Ulmus and Urticaceae have also been related to this process. Nevertheless, the increase in the SPI of Castanea and Chenopodiaceae/Amaranthaceae, with pollen seasons in summer and spring-summer, respectively, may be associated with greater insolation during the positive phase of the WeMO. Conversely, the relationships between the SPI of Platanus, Poaceae and Urticaceae and climatic indices were not clear, with both positive and negative correlations observed. Although the Poaceae SPI was negatively correlated with the winter NAO in Córdoba (southern Spain) (Smith et al. 2009), in Catalonia this was only negatively correlated with the annual AOi and positively with the annual WeMOi.

Positive correlations between Length of the pollen season and the climatic indices obtained for Artemisia, Cupressaceae, Olea, Pinus, Pistacia, Poaceae, Polygonaceae, total Quercus, Quercus deciduous type and Quercus evergreen type and Urticaceae observed in Catalonia $(71 \%)$, which were linked to drier years with higher insolation. However, the relationship between End of the pollen season and the climatic indices did not show a clear pattern for most pollen taxa. The number of positive $(45 \%)$ and negative $(55 \%)$ correlations were balanced, and the sign of correlation varied depending on the pollen taxon. In addition, End was the pollen season parameter 
least correlated with teleconnection patterns, despite the fact that 44 correlations were obtained and 15 of them were with the annual WeMOi. End dates for Cupressaceae and Fraxinus were not correlated with climatic indices. In contrast, negative correlations between the End date for Cupressaceae and the NAO in March and February-March periods in Central Italy were found, which could primarily be ascribed to the relationship between the winter NAO and winter air temperature (Dalla Marta et al. 2011).

Results suggest that the greatest influence of Northern Hemisphere teleconnection patterns occurs in spring flowering taxa (i.e. Olea, Pinus, Plantago, Quercus), but the cases in summer (Artemisia) and winter (i.e. Cupressaceae, Fraxinus, Ulmus) are not negligible.

The NAO and AO showed positive trends for much of the 1970s and 1980s, with historic peaks in the early 1990s, and it has been suggested that they contributed significantly to the global warming signal (Hurrell 1995, Cohen \& Barlow 2005). Although NAO and AO trends during the period 1984-2011 were slightly negative (Fig. 2), our results showed that when positive phases of these indices occurred, a decrease in the SPI and an advance and enlargement of the pollen season were observed. These observations agree with those in previous studies that showed an increase in the length of the active growing season of terrestrial plants in the northern part of the Northern Hemisphere (Myneni et al. 1997), and particularly in Europe (Menzel \& Fabian 1999), as a result of warming during the winterspring period in the last decades, possibly related to positive NAOi values. Besides, there is an evident signal of advanced leaf unfolding, flowering and fruiting in wild plants all across Europe in almost $80 \%$ of the records (Menzel et al. 2006). It is quite obvious that changes in pollination may affect the prevalence and severity of allergic diseases, but what are the ecological effects? Changes in severity and timing of the pollen season may have direct effects, e.g., on the timing and quantity of fruit production, but they could also indirectly alter other ecological processes. Responses by individual species to climate change are connected through interactions with other species at the same or adjacent trophic level (Walther 2010). For instance, some evidence indicates that warmer spring weather in Europe has disrupted the synchrony between caterpillars Operophtera brumata and oak budburst (Visser \& Holleman 2001), leading to a mismatch between the peak of insect availability and the peak demands of insectivorous bird nestlings (Visser et al. 2006). Therefore, the timing of change in different taxonomic groups is not always synchronous and may have huge ecological consequences, although some communities are already undergoing reassembly (Both \& Visser 2005).

The WeMO showed a negative phase throughout the nineteenth century and a positive one in the twentieth century up to the late 1960s. Opposite phases of similar periodicities during the second half of the twentieth century between the AO and WeMO have been observed, which seem to show an increase in the modulation of the Mediterranean pattern by the Arctic pattern in the last few decades (Martín-Vide \& López-Bustins 2006). Negative correlation between the annual WeMO and AO indices was also observed during the period 1994-2011; however, it was nonsignificant, and a decreasing trend was detected for the WeMO during our study period, which was significant for the annual timeframe. Considering that the WeMOi was the climatic index best correlated with pollen parameters, more research is needed to confirm the above-mentioned trend of the WeMOi in the future, as it could be used as an indicator to predict pollen production, timing and the length of pollen season in the western Mediterranean basin.

\section{CONCLUSIONS}

Results showed that pollen production and the timing (start and length) of the pollen season can partly be explained as an effect of Northern Hemisphere teleconnection patterns, suggesting the possibility of predicting the onset and severity of pollination through their atmospheric modes. In general a link between an increase in pollen production for most pollen taxa studied and an increase in rainfall was detected in Catalonia during the negative phase of climatic indices. Furthermore, the pollen season was observed to be advanced and extended in years in which the indices had high positive values (i.e. characterized by less rainfall and higher insolation and temperatures in the western Mediterranean basin). However, the relationship between the End of the pollen season and climatic indices did not show a clear pattern for most pollen taxa. Finally, we interpreted negative correlations between the SNAOi and SPI of Ambrosia, Chenopodiaceae/Amaranthaceae, Fraxinus, Olea, Pinus, Platanus, total Quercus, Quercus evergreen type, Ulmus and Urticaceae as a washing-out effect.

These data on the timing and magnitude of the pollen season are valuable for the prevention and 
treatment of allergic diseases. According to the persistent duration of the NAO and $\mathrm{AO}$ in their positive phases since 1970-although showing a slightly declining trend over the last 2 decades - a decrease in the SPI accompanied by an advance and enlargement of the pollen season is expected in the western Mediterranean basin. Furthermore, WeMO variability plays a key role in the production and timing of the pollen season on the Iberian Peninsula. The negative trend observed for WeMOi during our study period needs to be confirmed in order to identify its effects on ecosystems and public health. Intensifying efforts to clarify the dependencies and strengths of the linkages between different Northern Hemisphere teleconnection patterns and ecological processes, while also taking into account the complexity of ecosystems, would also be advisable.

Acknowledgements. We acknowledge financial support from the European Commission for ENV4-CT98-0755; from the Spanish Government for AMB97-0457-CO7-021, REN 2001-10659-CO3-01，CGL2004-21166-E，CGL2005-07543/ CLI, CGL2009-11205, CGL2012-39523-C02-01/CLI, CGL201239523-C02-02 and CONSOLIDER GRACCIE; from the Catalan Government AGAUR for 2002SGR00059, 2005S GR00519, 2009SGR1102 and 2014SGR1274; and from the Diputació de Tarragona, Servei Meteorològic de Catalunya, Sociedad Española de Alergología e Inmunología Clínica (SEAIC), División de Alergia de Laboratorios LETI S.L. Barcelona, Societat Catalana d'Al-lèrgia i Immunologia Clínica (SCAIC), Stallergenes Ibérica, S.A., J Uriach y Compañia, S.A., LAFOSCA STUDIO SL, and Fundació Catalunya-La Pedrera. Also thanks to Ileana Baldé (Universitat de Barcelona) for the summer NAO data and to Javier Martín-Vide and Joan Albert López-Bustins, Group of Climatology (University of Barcelona), for WeMOi data.

\section{LITERATURE CITED}

Ambaum MHP, Hoskins BJ, Stephenson DB (2001) Arctic Oscillation or North Atlantic Oscillation? J Clim 14: 3495-3507

Andersen TB (1991) A model to predict the beginning of the pollen season. Grana 30:269-275

$>$ Avolio E, Pasqualoni L, Federico S, Fornaciari M and others (2008) Correlation between large-scale atmospheric fields and the olive pollen season in Central Italy. Int J Biometeorol 52:787-796

Barnston AG, Livezey RE (1987) Classification, seasonality and persistence of low-frequency atmospheric circulation patterns. Mon Weather Rev 115:1083-1126

Belmonte J, Vendrell M, Roure JM, Vidal J, Botey J, Cadahía A (2000) Levels of Ambrosia pollen in the atmospheric spectra of Catalan aerobiological stations. Aerobiologia 16:93-99

Belmonte J, Alarcón M, Avila A, Izquierdo R, Cuevas E (2008a) Foreign allergenic pollen. Some cases observed in Catalonia (NE Spain) and Tenerife (Canary Islands). Allergy 63(Suppl 88):104-105
Belmonte J, Alarcón M, Avila A, Scialabba E, Pino D (2008b) Long-range transport of beech (Fagus sylvatica L.) pollen to Catalonia (north-eastern Spain). Int J Biometeorol 52: 675-687

> Bladé I, Liebmann B, Fortuny D, van Oldenborgh GJ (2012) Observed and simulated impacts of the summer NAO in Europe: implications for projected drying in the Mediterranean region. Clim Dyn 39:709-727

Bolle HJ (2003) Mediterranean climate (variability and trends). Springer, Berlin

Both C, Visser ME (2005) The effect of climate change on the correlation between avian life history traits. Glob Change Biol 11:1606-1613

Bringfelt B, Engstrom I, Nilsson S (1982) An evaluation of some models to predict airborne pollen concentration from meteorological conditions in Stockholm, Sweden. Grana 21:59-64

Clot B (2003) Trends in airborne pollen: an overview of 21 years of data in Neuchâtel (Switzerland). Aerobiologia 19:227-234

Cohen J, Barlow M (2005) The NAO, the AO, and global warming: how closely related? J Clim 18:4498-4513

$>$ D'Odorico P, Yoo J, Jaeger S (2002) Changing seasons: an effect of the North Atlantic Oscillation? J Clim 15: 435-445

Dalla Marta A, Grifoni D, Torrigiani Malaspina T, Cecchi L, Barbano F, Mancini M, Orlandini S (2011) The effects of large-scale atmospheric fields on the cypress pollen season in Tuscany (Central Italy). Aerobiologia 27:213-220

Emberlin J, Savage M, Jones S (1993) Annual variations in grass pollen seasons in London 1961-1990: trends and forecast models. Clin Exp Allergy 23:911-918

Emberlin J, Laaidi M, Detandt M, Gherig R and others (2007) Climate change and evolution of the pollen content of the air in seven European countries: the example of birch. Rev Fr Allergol 47:57-63

> Fernández-Llamazares A, Belmonte J, Alarcón M, LópezPacheco M (2012) Ambrosia L in Catalonia (NE Spain): expansion and aerobiology of a new bioinvader. Aerobiologia 28:435-451

Galán C, García-Mozo H, Vázquez L, Ruiz L, Díaz de la Guardia C, Trigo MM (2005) Heat requirement for the onset of the Olea europaea L pollen season in several sites in Andalusia and the effect of the expected climate change. Int J Biometeorol 49:184-188

Galán Soldevilla C, Cariñanos González P, Alcázar Teno P, Domínguez Vilches E (2007) Manual de calidad y gestión de la Red Española de Aerobiología. Servicio de Publicaciones, Universidad de Córdoba

> Goodess CM, Jones PD (2002) Links between circulation and changes in the characteristics of Iberian rainfall. Int J Climatol 22:1593-1615

Gouveia C, Trigo RM, DaCamara CC, Libonati R, Pereira JM (2008) The North Atlantic Oscillation and European vegetation dynamics. Int J Climatol 28:1835-1847

- Hirst JM (1952) An automatic volumetric spore trap. Ann Appl Biol 39:257-265

Hurrell JW (1995) Decadal trends in the North Atlantic Oscillation: regional temperatures and precipitation. Science 269:676-679

> Hurrell JW, Deser C (2010) North Atlantic climate variability: the role of the North Atlantic Oscillation. J Mar Syst 79:231-244

Hurrell JW, Kushnir Y, Visbeck M, Ottersen G (2003) An overview of the North Atlantic Oscillation. In: Hurrell 
JW, Kushnir Y, Visbeck M, Ottersen G (eds) The North Atlantic Oscillation: climate significance and environmental impact. Geophysical Monograph Series, American Physical Union, Washington, DC, p 1-35

Hurrell J \& National Center for Atmospheric Research staff (eds) (2014) The climate data guide: Hurrell North Atlantic Oscillation (NAO) Index (station-based). Available at: https://climatedataguide.ucar.edu/climate-data/ hurrell-north-atlantic-oscillation-nao-index-station-based (accessed 28 October 2015)

Jäger S, Nilsson S, Berggren B, Pessi AM, Helander M, Ramfjord H (1996) Trends of some airborne tree pollen in the Nordic countries and Austria, 1980-1993. A comparison between Stockholm, Trondheim, Turku and Vienna. Grana 35:171-178

Jato V, Rodríguez-Rajo FJ, Méndez J, Aira MJ (2002) Phenological behaviour of Quercus in Ourense (NW Spain) and its relationship with the atmospheric pollen season. Int J Biometeorol 46:176-184

Jochner S, Menzel A (2015) Does flower phenology mirror the slowdown of global warming? Ecol Evol 5:2284-2295

> Jones PD, Jonsson T, Wheeler D (1997) Extension to the North Atlantic Oscillation using early instrumental pressure observations from Gibraltar and South-West Iceland. Int J Climatol 17:1433-1450

López-Bustins JA, Martín-Vide J, Sanchez-Lorenzo A (2008) Iberia winter rainfall trends based upon changes in teleconnection and circulation patterns. Glob Planet Change 63:171e176

Martín-Vide J, López-Bustins JA (2006) The Western Mediterranean Oscillation and rainfall in the Iberian Peninsula. Int J Biometeorol 26:1455-1475

> Menzel A, Fabian P (1999) Growing season extended in Europe. Nature 397:659

Menzel A, Sparks TH, Estrella N, Koch E and others (2006) European phenological response to climate change matches the warming pattern. Glob Change Biol 12: 1969-1976

Muñoz-Díaz D, Rodrigo FS (2003) Effects of the North Atlantic Oscillation on the probability for climatic categories of local monthly rainfall in southern Spain. Int J Biometeorol 23:381-397

> Myneni RB, Keeling CD, Tucker CJ, Asrar G, Nemani RR (1997) Increased plant growth in the northern high latitudes from 1981 to 1991. Nature 386:698-702

Nielsen AB, Møller PF, Giesecke T, Stavngaard B, Fontana SL, Bradshaw RHW (2010) The effect of climate conditions on inter-annual flowering variability monitored by pollen traps below the canopy in Draved Forest, Denmark. Veget Hist Archaeobot 19:309-323

> Osborn T (2006) Recent variations in the winter North Atlantic Oscillation. Weather 61:353-355

> Quadrelli R, Pavan V, Molteni F (2001) Wintertime variability of Mediterranean precipitation and its links with large-scale circulation anomalies. Clim Dyn 17:457-466

Smith M, Emberlin J, Stach A, Ranatio-Lehtimäki A and others (2009) Influence of the North Atlantic Oscillation on grass pollen counts in Europe. Aerobiologia 25:321-332

Sommer J, Rasmussen A (2008) Pollen \& Sporemålinger i DanmarkSæsonen 2008. Astma-Allergi Forbundet and

Editorial responsibility: Tim Sparks,

Cambridge, UK
Danmarks Meteorologiske Institut, Copenhagen

Stach A, Smith M, Prieto Baena JC, Emberlin J (2008a) Long-term and short-term forecast models for Poaceae (grass) pollen in Pozna, Poland, constructed using regression analysis. Environ Exp Bot 62:323-332

Stach A, Emberlin J, Smith M, Adams-Groom B, Myszkowska D (2008b) Factors that determine the severity of Betula spp. pollen seasons in Poland (Pozna and Krakow) and the United Kingdom (Worcester and London). Int J Biometeorol 52:311-321

Stenseth NC, Mysterud A (2005) Weather packages: finding the right scale and composition of climate in ecology. J Anim Ecol 74:1195-1198

Stenseth NC, Mysterud A, Ottersen G, Hurrell JW, Chan KS, Lima M (2002) Ecological effects of climate fluctuations. Science 297:1292-1296

Stenseth NC, Ottersen G, Hurrell JW, Mysterud A and others (2003) Studying climate effects on ecology through the use of climate indices: the North Atlantic Oscillation, El Niño Southern Oscillation and beyond. Proc R Soc Lond B 270:2087-2096

Teranishi H, Kenda Y, Katoh T, Kasuya M, Oura E, Taira H (2000) Possible role of climate change in the pollen scatter of Japanese cedar Cryptomeria japonica in Japan. Clim Res 14:65-70

Thompson DWJ, Wallace JM (2000) Annular modes in the extratropical circulation, Part I: month-to-month variability. J Clim 13:1000-1016

Tildes Gomes P (2000) Relationships between Iberian rainfall variability and the North Atlantic Oscillation international scientific meeting on the detection and modelling of recent climate change and its effects on a regional scale. Springer, Tarragona

- Van Vliet AJH, Overeem A, De Groot R, Jacobs AFG, Spieksma FTM (2002) The influence of temperature and climate change on the timing of pollen release in The Netherlands. Int J Climatol 22:1757-1767

- Visser ME, Holleman LJM (2001) Warmer spring disrupt the synchrony of oak and winter month phenology. Proc R Soc Lond B 268:289-294

> Visser ME, Holleman LJM, Gienapp P (2006) Shifts in caterpillar biomass phenology due to climate change and its impact on the breeding biology of an insectivorous bird. Oecologia 147:164-172

> Von Storch H, Zorita E, Cubasch U (1993) Downscaling of global climate change estimates to regional scales: an application to Iberian rainfall in wintertime. J Clim 6: 1161-1171

Wallace JM (2000) North Atlantic Oscillation annular mode: two paradigms-one phenomenon. QJR Meteorol Soc 126:791-805

Walther GR (2010) Community and ecosystem responses to recent climate change. Philos Trans R Soc Lond B Biol Sci 365:2019-2024

Zhou S, Miller AJ, Wang J, Angell JK (2001) Trends of NAO and $\mathrm{AO}$ and their associations with stratospheric processes. Geophys Res Lett 28:4107-4110

Ziello C, Sparks TH, Estrella N, Belmonte J and others (2012) Changes to airborne pollen counts across Europe. PLoS ONE 7:e34076

Submitted: June 10, 2015; Accepted: September 9, 2015

Proofs received from author(s): October 30, 2015 